\title{
Pyloric Stenosis in Preterm Identical Twins of a Triplet Birth with a Review of Pyloric Stenosis in Premature Neonates
}

\author{
Darlene $\mathrm{AC}^{1 *}$ and Paul $\mathrm{DD}^{2}$ \\ ${ }^{1}$ Division Chief Neonatology, Professor of Paediatrics University of Central Florida College of Medicine, Nemours Children's Hospital, USA \\ ${ }^{2}$ Chief Division of Paediatric Surgery, Johns Hopkins All Children's Hospital, USA \\ *Corresponding author: Darlene A Calhoun, D.O, Division Chief Neonatology, Professor of Paediatrics, University of Central Florida College of \\ Medicine, Nemours Children's Hospital, 13535 Nemours Parkway, Orlando, FL 32827, USA
}

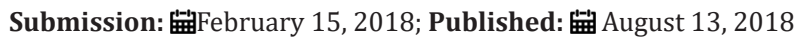

\begin{abstract}
Pyloric stenosis occurs in 1 of every 200-300 live births and is four times more common in males than in females. Reports of pyloric stenosis in premature neonates are rare. We present a case of pyloric stenosis in premature female identical twins of a triplet birth whose father also had pyloric stenosis. The incidence of pyloric stenosis in premature infants and in identical twins, the age and manner of presentation and the clinical courses of these infants is presented. The potential mode of genetic inheritance is also reviewed.
\end{abstract}

Keywords: Hypertrophic pyloric stenosis; Pyloromyotomy; Prematurity

Abbreviations: EGA: Estimated Gestational Age; NICU: Neonatal Intensive Care; DOL: Day of Life; CGA: Corrected Gestational Age; OR: Operating Room

\section{Introduction}

Pyloric stenosis remains the most common cause of intestinal obstruction in infants. It occurs in 1 of every 200-300 live births and is four times more common in males [1,2]. The condition may run in families and affected infants are more likely to have blood types B or 0 [3]. In premature neonates, symptoms are subtle, and pyloric stenosis has been reported rarely [4].

We describe neonates delivered of a triplet pregnancy, in which two of the neonates were identical twins and both developed pyloric stenosis. The father had pyloric stenosis as an infant. We review the presentation of pyloric stenosis in these neonates, and review the literature related to pyloric stenosis in identical twins, in premature infants, and in children of parents who had pyloric stenosis as an infant.

\section{Patient presentations}

The triplets were born to a $35 \mathrm{y} / \mathrm{o}$ mother whose pregnancy was initially two fertilized ova in which one ovum subsequently split. The mother had a history of post-partum haemorrhage in a previous pregnancy resulting in sensitization to Anti-E and Anti-C. The pregnancy was uncomplicated except for the triplet gestation, preterm labor, and the potential for transplacental transfer of haemolytic antibodies.
At 29 4/7 weeks gestation, the mother underwent an emergency Caesarean section secondary to abruptio placenta. Apgar scores on Baby Girls A and B were 9 at one minute and five minutes. Baby Girl C had Apgar scores of 8 at one minute and 9 at 5 minutes. Each infant required intubation and surfactant administration in the operating room (or), and all were admitted to the neonatal intensive care unit (NICU). Birth weights were 990, 1020 and 1260 grams, respectively for Girls A, B, and C. Triplets B and C were noted to be the identical twins.

The infants progressed well as developing premature infants. Triplet B was started on feedings on day of life (DOL) \#7, and full feedings were reached on DOL \#20. The feedings, a combination of breast milk and Enfamil premature $24 \mathrm{cal} / \mathrm{oz}$ formula, were well tolerated with no gastric residuals, abdominal distension or formula intolerance. On DOL \#57, at a corrected gestational age (CGA) of $37.5 \mathrm{wks}$, she had a residual consisting of $30 \mathrm{~mL}$ of a $40 \mathrm{~mL}$ feeding. Her physical examination was benign, her abdominal girth remained stable, and the abdominal film obtained at that time showed a paucity of gas in the intestine. There was no evidence of obstruction or necrotizing enterocolitis. Subsequent feedings continued to have intermittent residuals consisting of clear gastric secretions and partially digested formula. At this time, the 
father acknowledged that he had pyloric stenosis as an infant. An ultrasound of the abdomen on DOL \#60 was equivocal for the diagnosis of pyloric stenosis, so the infant was transferred to a children's hospital with paediatric surgical services for further evaluation. A repeat ultrasound of the pylorus in this now $2.1 \mathrm{~kg}$ infant showed a wall thickness of $4 \mathrm{~mm}$ and channel length of $20 \mathrm{~mm}$, findings consistent with pyloric stenosis. The infant's electrolytes were corrected, and she underwent Pyloromyotomy via a transumbilical technique on DOL \#63 [5]. After surgery, the infant's feedings were gradually advanced. On post-op day \#6 she achieved full enteral feedings, and she was able to be discharged to home on DOL \#84 at a CGA of 41.4 wks.

Triplet C had feedings started on DOL \#4. Her feedings were also a combination of breast milk and Enfamil premature $24 \mathrm{cal} / \mathrm{oz}$ formula, which were well tolerated. On DOL \#81 and a corrected gestational age of 41.1 weeks, she developed projectile vomiting. An abdominal ultrasound was performed, and she too was transferred for surgical evaluation. The abdominal ultrasound on DOL \#83 in this $2.8 \mathrm{~kg}$ baby revealed a pyloric wall thickness of $4 \mathrm{~mm}$ and channel length of $17 \mathrm{~mm}$. The patient underwent Pyloromyotomy by a laparoscopic technique [6]. She achieved full enteral feedings on post-op day \#3 and was able to be discharged to home on DOL $\# 82$ at a CGA of $41.2 \mathrm{wks}$.

Triplet A remained asymptomatic and was discharged to home on DOL \#56 at a CGA of 37.4wks. She had an uneventful hospital course for a premature newborn infant.

\section{Discussion}

The earliest accounts of pyloric stenosis were given by Patrick Blair in 1717 and Hezekia Beardsley in 1788 [7]. However, it wasn't until 1888 when the Danish paediatrician, Hirsch sprung, established the condition as an entity when he described two cases [2].

Pyloric stenosis occurs in 1 of every 200-300 live births and is four times more common in males [1,2]. It is rare in Asians and is two to three times more common in Caucasian than African American infants [8]. Although usually an isolated anomaly, $7 \%$ of infants will have other conditions such as intestinal mal-rotation, urinary tract obstruction, and oesophageal atresia [2].

As was the case for the identical twins presented in this case, it is recognized that if one twin develops pyloric stenosis, 80$90 \%$ of the time the other twin will as well [9-11]. Early cases of monozygotic twins in which only one member was affected were first reported by Lasch and Sheldon [11,12].

While pyloric stenosis is reported to occur more frequently in first born males [8], our patients were both females. They were the third pregnancy for this mother and the first for this father. In addition, their blood types were A positive, while blood types B and $\mathrm{O}$ tend to occur more frequently in patients with pyloric stenosis [3].

Schechter et al. [13] noted that pyloric stenosis was diagnosed later in premature infants than in term infants, although when measured in terms of post-conceptual age, it is actually an earlier presentation. In our patients, the age of diagnoses were $8.5 \mathrm{wks}$ and $12 \mathrm{wks}$, compared to the range of 3 to 8 weeks in term infants. Yang et al. [9] reported a lag time between the developments of pyloric stenosis in twins. In their series of twins with EGAs between 32 and 35 weeks, the length in time between diagnoses in each twin pair was 1 to 4 weeks. In our patients, there was 24 days between the symptomatic developments of pyloric stenosis. The longer time between diagnoses in our patients may have been related to their younger EGA of 29.4wks.

In 1928, Cockayne et al. [14] reviewed cases of parents who had pyloric stenosis and subsequently, whose infants developed pyloric stenosis. Of the 212 families they studied, 528 children were born and 221 were affected with pyloric stenosis. Of these, 185 were males and 36 were females. Parents who have had pyloric stenosis as an infant have a $10-20 \%$ chance of having a child who also has pyloric stenosis. In our patients, the father had pyloric stenosis repair as an infant.

While a contrasted upper gastrointestinal series has historically been the method of confirming pyloric stenosis, this has been gradually replaced by ultrasonography [15]. The diagnostic criteria for ultrasound focus on two measurements: muscle wall thickness and channel length. In 1932, Meuwissan and Slcof were the first to report measurements of the pyloric channel and comparisons of lengths in affected infants [7]. Currently, the diagnostic ranges for muscle wall thickness and channel length are $3-4.8 \mathrm{~mm}$ for muscle thickness, and from 12 to $19 \mathrm{~mm}$ for channel length [16]. A retrospective review of 190 infants found a strong correlation between infant weight and channel length, although not muscle thickness, which may impact diagnostic criteria for premature infants [17]. Another study of 87 patients found the muscle thickness and channel length were less in premature infants but this difference did not reach statistical significance [18]. In this same study, prematurity did not influence the sensitivity or specificity of diagnostic ultrasound which emphasizes the point that realtime evaluation of the pyloric channel opening and antropyloric peristaltic activity by the ultra-sonographer are important adjuncts [16].

Although the natural course of the condition is for the hypertrophy to resolve after several weeks, survival rates for infants in the pre-surgical era were dismal due to their succumbing to dehydration and malnutrition. Early surgical procedures included gastroenterostomy, pyloroplasty, and forcible dilatation via gastrostomy [2]. It was not until 1912 when Ramstedt described the Pyloromyotomy technique, a curative development touted as being one of the most "outstandingly successful operations" in the history of surgery [7]. In 1986, Tan and Bianchi reported using a circum-umbilical incision approach thus leaving no visible post-operation scar [6]. Laparoscopy has also been employed and several randomized controlled trials have shown that laparoscopy can be as safe and effective as open Pyloromyotomy [19].

In summary, pyloric stenosis can be subtle with non-distinct symptoms in the premature infant. Due to other conditions 
associated with prematurity, the findings of emesis and gastric residuals must be fully evaluated in view of other potential surgical conditions such as necrotizing enterocolitis, malrotation and volvulus. A high index of suspicion for pyloric stenosis can facilitate the obtaining of ultrasonography necessary to make the final diagnosis.

\section{Contributor's Statement Page}

Dr. Calhoun composed the initial manuscript and prepared the manuscript in the format for submission to Paediatrics. Dr. Danielson participated in the revising of the manuscript and contributed significantly to the writing of the portion of the manuscript dealing with the surgical management of neonates with pyloric stenosis. Both authors have given final approval of the version submitted for publication.

\section{References}

1. Hara S, Crump EP, Parker WG (1966) Pyloric stenosis: The incidence of infantile hypertrophic pyloric stenosis in the Negro infant. J Natl Med Assoc 58(4): 250-253.

2. Singh J BR (2010) Paediatrics, Pyloric Stenosis. Up to Date.

3. Dodge JA (1967) ABO blood groups and infantile hypertrophic pyloric stenosis. Br Med J 4(5582): 781-782.

4. Wilson MG (1960) Pyloric stenosis in premature infants. The Journal of Pediatrics 56: 490-497.

5. Leinwand MJ, Shaul DB, Anderson KD (2000) A standardized feeding regimen for hypertrophic pyloric stenosis decreases length of hospitalization and hospital costs. J Pediatr Surg 35(7): 1063-1065.

6. Najmaldin A, Tan HL (1995) Early experience with laparoscopic Pyloromyotomy for infantile hypertrophic pyloric stenosis. J Pediatr Surg 30(1): 37-38.
7. Cremin BJ, Klein A (1968) Infantile pyloric stenosis: a 10-year survey. S Afr Med J 42(39): 1056-1060.

8. MacMahon B (2006) The continuing enigma of pyloric stenosis of infancy: a review. Epidemiology 17(2): 195-201.

9. Yang G, Brisseau G, Yanchar NL (2008) Infantile hypertrophic pyloric stenosis: An association in twins? Paediatr Child Health 13(5): 383-385.

10. Yen JB, Kong MS, Wu WJ, Huang CS, Chang KW (2003) Idiopathic hypertrophic pyloric stenosis in identical twins Chang Gung Med J 26(12): 933-936.

11. Lewis FL (1944) Pyloric stenosis in identical twins. British Medical Journal 1(4336): 221

12. Cockayne EA, Sheldon WP (1928) Hypertrophic Pyloric Stenosis in Uniovular Twins. Proc R Soc Med 21(7): 1260-1261.

13. Schechter R, Torfs CP, Bateson TF (1997) The epidemiology of infantile hypertrophic pyloric stenosis. Paediatr Perinat Epidemiol 11(4): 407427.

14. Cockayne EA, Moncrieff AA, Sheldon WP (1928) Familial Cases of Hypertrophic Pyloric Stenosis. Proc R Soc Med 21(7): 1261-1262.

15. Hernanz-Schulman M (2009) Pyloric stenosis: role of imaging. Pediatr Radiol. Suppl 2: S134-S139.

16. Stunden RJ, LeQuesne GW, Little KE (1986) The improved ultrasound diagnosis of hypertrophic pyloric stenosis. Pediatr Radiol 16(3): 200205.

17. Haider N, Spicer R, Grier D (2002) Ultrasound diagnosis of infantile hypertrophic pyloric stenosis: determinants of pyloric length and the effect of prematurity. Clin Radiol 57(2): 136-139.

18. Forster N, Haddad RL, Choroomi S, Dilley AV, Pereira J (2007) Use of ultrasound in 187 infants with suspected infantile hypertrophic pyloric stenosis. Australas Radiol 51(6): 560-563.

19. Oomen MW, Hoekstra LT, Bakx R, Ubbink DT, Heij HA (2012) Open versus laparoscopic pyloromyotomy for hypertrophic pyloric stenosis: a systematic review and meta-analysis focusing on major complications. Surg Endosc 26(8): 2104-2110.

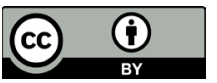

Creative Commons Attribution 4.0 International License

For possible submissions Click Here

\section{Submit Article}

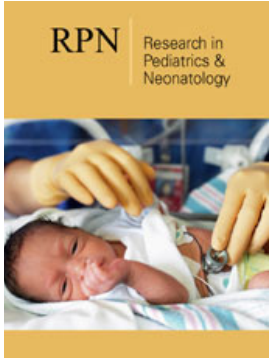

\section{Research in Pediatrics \& Neonatology}

Benefits of Publishing with us

- High-level peer review and editorial services

- Freely accessible online immediately upon publication

- Authors retain the copyright to their work

- Licensing it under a Creative Commons license

- Visibility through different online platforms 